\section{Case Reports in Oncology}

Case Rep Oncol 2019;12:434-442

DOI: $10.1159 / 000501200$

Published online: June 13, 2019

(C) 2019 The Author(s)

Published by S. Karger AG, Base

www.karger.com/cro

This article is licensed under the Creative Commons Attribution-NonCommercial 4.0 International License (CC BY-NC) (http://www.karger.com/Services/OpenAccessLicense). Usage and distribution for commercial purposes requires written permission.

\title{
Diagnosis of Mixed Adenoneuroendocrine Carcinoma (MANEC) after Neoadjuvant Chemotherapy for Pancreatic and Gastric Adenocarcinoma: Two Case Reports and a Review of the Literature
}

\author{
Ester Oneda ${ }^{a} \quad$ Barbara Liserre $^{b} \quad$ Denise Bianchi $^{b} \quad$ Luigina Rota $^{a}$ \\ Giordano Savellic ${ }^{c}$ Fausto Zorzi ${ }^{b}$ Alberto Zaniboni ${ }^{a}$ \\ aDepartment of Clinical Oncology, Fondazione Poliambulanza, Brescia, Italy; ${ }^{b}$ Department \\ of Pathology, Fondazione Poliambulanza, Brescia, Italy; 'Department of Nuclear Medicine, \\ Fondazione Poliambulanza, Brescia, Italy
}

\section{Keywords}

Mixed adenoneuroendocrine carcinoma - Neoadjuvant chemotherapy $\cdot$ Neuroendocrine differentiation

\begin{abstract}
Mixed adenoneuroendocrine carcinoma (MANEC) is a rare tumor of the gastrointestinal tract involving both epithelial and neuroendocrine (NE) components, each of which represents at least $30 \%$ of the tumor. Because of the low frequency of this histotype, only a few cases have been described. In this report we discuss two cases treated with neoadjuvant chemotherapy: a pancreatic adenocarcinoma and a gastric adenocarcinoma. The histopathological specimens examined after surgery showed an additional NE component with a possible indication of the MANEC histotype. We hypothesize two possible explanations: tumor NE cells are more chemoresistant than adenocarcinoma cells, and cytotoxic injury induces NE differentiation in tumor cells. The clinical significance and prognostic value of endocrine differentiation, however, remain controversial issues.

(C) 2019 The Author(s)

Published by S. Karger AG, Basel
\end{abstract}




\section{Introduction}

Mixed adenoneuroendocrine carcinoma (MANEC) is a rare tumor with dual adenocarcinomatous and neuroendocrine differentiation, in which each component represents at least $30 \%$ of the tumor [1]. Diagnosis is mainly based on tumor cytology and architecture and is completed by immunostaining with specific neuroendocrine markers, such as chromogranin, synaptophysin, and CD56 (for the neuroendocrine component), combined with markers of non-endocrine differentiation, such as keratin 7 (for gastric tumors) and keratin 20, CDX2, and carcinoembryonic antigen (CEA) [2]. To date, according to literature, MANECs has been identified in various organs, such as the stomach [3], colon [4], biliary tract [5], pancreas, and even the uterine cervix [6]. A large retrospective case-matched study on patients with MANEC by Watanabe et al., reported 3.2\% prevalence of MANEC among all patients with colorectal cancer, as determined from hospital records [7]. It is unclear whether MANEC is more biologically similar to the neuroendocrine or to the adenocarcinoma parts. However, it is an extremely rare tumor, with the majority of instance presented in case reports. Due to its rarity, few aspects regarding the origin or the best therapeutic options are known. The latest WHO recommendations suggest that MANECs should be treated as an adenocarcinoma; however, recent evidence, according to numerous authors, indicates that treatment should be based on the most aggressive histologic component $[2,8,9]$. Due to the rarity of these tumors, there is a significant ongoing debate regard the best treatment for MANECs. These tumors did not exhibit specific symptoms nor did specific radiological or laboratory tests of them reveal unique findings; hence, a diagnosis depends on postoperative histopathological and immunohistochemical studies. There is also conflicting evidence regarding the prognosis of patients with MANEC [10].

In this paper, we present two unusual cases of MANECs: one arising from the pancreas and one from the stomach. These diagnoses were made based on surgical specimens acquired after administration of neoadjuvant chemotherapy for adenocarcinoma tumors.

\section{Case Report}

\section{Case 1}

For a 54-years-old male high levels of transaminases were accidentally detected in a blood test. Therefore, an abdomen ultrasound (US) was performed and revealed a nodule in the head of the pancreas. In June 2018, computed tomography (CT) on the abdomen showed a neoplasm in the head of the pancreas that was in contact with the duodenal wall and featured an important dilatation of the extra-biliary and intra-biliary tracts of the liver, gallbladder and major pancreatic duct. Small lymph nodes were present near the pancreas. The patient was admitted to our hospital and underwent an endoscopic retrograde cholangiopancreatography (ERCP), with an insertion of biliary metallic prostheses, and an endoscopic ultrasound (EUS) biopsy. The cytological specimen confirmed the presence of malignant cells that were compatible with ductal adenocarcinoma.

To address the local extension of the disease, immediate surgery was not indicated. Instead, six cycles of FOLFIRINOX (fluorouracil [5-FU], leucovorin, irinotecan and oxaliplatin) chemotherapy were delivered, which resulted in a unique side effect of G1-like neuropathy in the hands. The reassessment using CT showed stable disease. However, the patient was hospitalized for a fever that was nonresponsive to antibiotic therapy, and diagnosed with cholangitis. Therefore, a biliary drain was placed using percutaneous transhepatic cholangiography 
Oneda et al.: Diagnosis of Mixed Adenoneuroendocrine Carcinoma (MANEC) after Neoadjuvant Chemotherapy

(PTC). The bile culture showed the presence of Enterococcus faecalis, Pseudomonas aeruginosa and Stenotrophomonas maltophilia. After delayed antibiotic therapy the patient no longer had a fever.

On November 2018, the patient underwent duodenum-cephalo-pancreasectomy with splenic vein tract resection, which was reconstructed with left renal vein segment interposition, and extensive right hemicolectomy with distal ileus-transverse anastomosis. Both biliodigestive and gastroenteric reconstruction in a single loop (following Child) and pancreatico-gastro anastomosis were performed.

Examination of the surgical specimen revealed that the neoplasm involved the ampullary region. The proximal and distal resected margins, principal biliary duct and pancreatic margin were free from tumor involvement. Histopathological examination of the surgical specimen confirmed tumor infiltration into the duodenal wall to the mucosa and the adipose tissue anteriorly and posteriorly to the pancreas, $<1 \mathrm{~mm}$ from the mesenteric vein and superior mesenteric artery. Metastases were present in 3 of the 25 regional lymph nodes. Angiolymphatic invasion, with perineural invasion was also present (ypT2N1, R1 stage). The tumor architecture was predominantly solid, consisting of clusters of glandular structures, with epithelial markers, such as CK19 and CK7, and neuroendocrine markers, such as synaptophysin and CD56. Focal mucus secretion was also seen in the same cells (focal PAS-D +). This pattern is characteristic of amphicrine MANEC, in which exocrine and neuroendocrine features are coexpressed by the same neoplastic cells, which show divergent differentiation as indicated by immunohistochemical or electron microscopic techniques [8]. The tumor cells were undifferentiated (G3) (Fig. 1).

The patient continued therapy with FOLFIRINOX for an additional four cycles and at the least assessment, he showed no evidence of recurrence.

\section{Case 2}

In June 2018, a 73-years-old man underwent a fecal occult blood test (FOBT) in a screen used to prevent colorectal cancer, and the test result was positive. However, the colonoscopy was negative. The patient underwent a gastroscopy (missing documentation) that detected edematous and ulcerated mucosa that extended $5 \mathrm{~cm}$ (at $27 \mathrm{~cm}$ from the dental arch) and a neo-formation of approximately $4 \mathrm{~cm}$ with irregular margins at the level of the gastric curvature between the body and antrum, which was ulcerated. Histology revealed intestinal gastric adenocarcinoma and in situ squamous cell carcinoma with severe dysplasia of the esophagus. CT results showed thickening of the gastric antrum wall and of the small gastric curve and the presence of locoregional pathological lymph nodes. Positron emission tomography (PET) results showed intense accumulation of the metabolic tracer at the gastric wall, the small gastric curvature, and in two lymph node formations (cT1N1M0). The patient underwent four cycles of neoadjuvant chemotherapy with docetaxel, oxaliplatin, and fluorouracil/leucovorin (FLOT). CT results showed a reduction in the wall thickness of the gastric antrum and a reduction in the volume of regional lymph nodes. A near total laparoscopic gastrectomy (LAD D2) was performed in October 2018. Gross examination of the surgical specimen revealed a 20 $\mathrm{mm} \times 10 \mathrm{~mm}$ tumor of the greater gastric curvature that invaded the gastric wall. The proximal and distal resected margins were free from tumor involvement. Histopathological examination of the surgical specimen confirmed tumor infiltration of mucosa, submucosa and muscularis, with metastasis found in 1 of 35 regional lymph nodes. Angiolymphatic invasion and peritumoral lymphocytic infiltrate, without perineural invasion, were also noted (ypT3N1, R0 stage). The tumor architecture was predominantly solid, consisting of clusters of glandular cells, marked by keratins 7 , and clusters of tubular cells with endocrine morphology, marked 
by synaptophysin, CD 56 and chromogranin (Fig. 2). The neuroendocrine component represented more than $30 \%$ of the tumor; this pattern characterizes composite glandular-neuroendocrine mixed tumor (mixed adenocarcinoma-G1/G2 NET) [8]. The patient underwent four additional cycles of adjuvant chemotherapy with the FLOT scheme. The treatment was well tolerated, with G2 fatigue and G1 diarrhea which disappeared after the introduction of pancreatic enzyme therapy. Restaging through use of CT at the end of chemotherapy indicated no signs of recurrence of the underlying disease. The results from esophagogastroduodenoscopy (EGDS) showed irregular mucosal areas of the esophagus due to chronic esophagitis with an erosive character; normal results of gastric resection and regular gastric stump followed.

\section{Discussion}

In the presented cases, tumor cells with $\mathrm{NE}$ differentiation manifested in tumor postresection specimens after neoadjuvant chemotherapy, unlike the paired tumors in pretreatment biopsy/cytology specimens. The low cellularity of the basal specimens (determined by fine needle aspiration, in the first case, and by the lack of material of the biopsy, in the second case) did not reveal the presence or percentage of NE cells before the start of chemotherapy. Indeed, we know that tumors have heterogeneous population [11]. The genetic heterogeneity that derives from a large numbers of cell divisions with the emergence of multiple mutations translates into phenotypic heterogeneity. Neoadjuvant drugs can act as biologic selective killers. Increased NE cells have been reported in different types of tumors, such as colorectal and prostatic adenocarcinomas, after neoadjuvant therapy [12-14], and the extent of NE cells appears to be related to the degree of cytotoxic insult and treatment response. NE cell hyperplasia is observed in a variety of inflammatory conditions, such as chronic pancreatitis and inflammatory bowel disease, suggesting that NE cells may be more resistant to inflammatory injury. The resistance of endocrine cells to pathological conditions, such as inflammation or drug-induced toxicity, is a recognized phenomenon [15]. In benign conditions, resistance of preexisting endocrine cells to inflammatory injury is exemplified by the apparent islet cell aggregation seen when exocrine cells are lost because of inflammatory atrophy in chronic pancreatitis. Chemotherapy, which promotes inflammation, can also induce selective endocrine cell proliferation [16]. There are two main hypotheses to explain why NE differentiation increases in frequency and density in treated adenocarcinomas [17]. First, tumor cells with NE differentiation may be more resistant to the cytotoxic insult caused by neoadjuvant therapy $[12,14]$. Second, cytotoxic injury may induce NE differentiation in tumor cells [12]. In the case of neoplasia, resistance of inherent endocrine cells in exocrine tumors to radiation and cytotoxic drugs has also been demonstrated in other organs, notably the prostate [18]. The endocrine cells are thought to represent a group of terminally differentiated cells that are in the quiescent stage of the cell cycle and are therefore less responsive to treatment effects. Recent studies have shown that NE-secreted products, such as serotonin, somatostatin, and bombesin, may influence tumor growth by promoting proliferation, invasiveness, metastatic potential, and angiogenesis and by conferring antiapoptotic capabilities in prostatic and colorectal carcinoma $[19,20]$. A more likely explanation for the increase in endocrine cells with treatment, therefore, relates to the possibility of endocrine differentiation of tumor cells induced by cytotoxic insult. Indeed, it is well known that differentiation and growth arrest are often associated processes. It has been shown in the human prostatic cancer cell line LNCaP that interleukin- 6 both mediates cell growth arrest and induces endocrine differentiation, indicating a connection between growth inhibition and endocrine differentiation in prostate 
cancer [18]. Cox et al. [21] showed that the androgen-independent LNCaP-derived cell line C4-2 also acquired endocrine characteristics in response to treatment with physiologic and pharmacologic agents that elevate intracellular cyclic adenosine monophosphate, indicating that cells representing later stages of tumor progression are also capable of differentiation. In light of these observations, for prostatic carcinoma cell lines, it is plausible to postulate that the increased endocrine cells in tumors with a more advanced treatment response might reflect the fact that tumor cells may respond to treatment by differentiation into endocrine cells thus acquire an endocrine phenotype. Moreover, in prostate cancer, Liu et al. discovered an immunocyte expression protein that induces inflammatory response gene expression and contributes to NE prostate cancer differentiation [22]. Trans-differentiation of cancer cells is also observed in lung adenocarcinoma after tyrosine kinase inhibitor (TKI) therapy. In those cases, the adenocarcinoma transforms into small-cell lung cancer (SCLC) when resistance develops [23]. The differentiation seems to start from the same EGFR mutation of the adenocarcinoma counterpart and develops activating mutations of PIK3CA, inactivating mutations of TP53, and RB1 loss [24].

\section{Conclusions}

The clinical significance of endocrine differentiation in post-treated adenocarcinomas is still a controversial issue. Unfortunately, most cases of MANEC seem to be missed through biopsy-based diagnosis (it is most often misdiagnosed as adenocarcinoma). Therefore, many patients with MANEC will receive neoadjuvant treatment as is established for adenocarcinoma $[25,26]$. Of note, in the majority of missed MANEC cases, immunohistochemistry for neuroendocrine markers is not performed; therefore, it is impossible to establish any prognostic markers. Because of its dual histological profile, both the clinical behavior and management of MANEC are substantially different from those of adenocarcinoma and are primarily influenced by the contribution of each component as well as the type of cells in the neuroendocrine component. La Rossa et al. reported that patients with MANEC composed of large neuroendocrine cells have better survival and clinical behavior than patients with nonlarge neuroendocrine cells (small-to-intermediate or mixed large-to-intermediate cells) [27]. With regard to localized gastric MANEC, relatively good survival was observed in the two most-recent large Asian studies [28, 29]. A recent Chinese study [30] that compared the outcome of gastroesophageal junction neuroendocrine neoplasms (GEJ-NENs) with other gastric neuroendocrine neoplasms (NENs) showed that NEC was more aggressive, with poorly differentiated morphology, than adenocarcinoma [31] and had a shorter survival than MANEC (25.2 vs. 73.3 months) [30]. Shia et al. reported [32] that the absence of an associated adenocarcinoma component was predictive of a worse outcome; however, previous studies about gastric or colorectal MANEC reported that there was no statistically significant difference in survival between MANECs and NEC [33, 34]. In this study, a number of GEJ-NECs were mixed with highgrade adenocarcinoma, the outcome of which is better than with pure NECs. In fact, the metastatic patterns of the two entities are different: regional lymph node metastasis of MANEC is more common, and distant metastasis frequently occurrs in NEC, indicating that the behavior of NEC may be more aggressive. In contrast, the latest and largest Western study reported very poor survival rates of localized gastric MANEC [35]. In some studies of colorectal carcinomas, a poorer prognosis was observed in patients with tumors that harbored chromogranin-positive cells [36-39], but in other studies, this outcome was not confirmed [4044]. Currently, there is no consensus regarding the prognostic significance of NE cells after 
neoadjuvant chemotherapy, and more studies are needed. Due to the small number of cases of reported MANEC, the clinical behavior is unclear. At present, it is generally agreed that surgery is the first line of treatment for cases with a resectable tumor. After radical resection, multimodal treatment with adjuvant radiotherapy and/or chemotherapy should be performed if indicated. However, it is still not clear whether the postoperative course and ideal management of cases of MANEC differ from those of cases of adenocarcinoma only or neuroendocrine carcinoma only. Lee et al. proposed that treatment should focus on the more aggressive cells of the tumor because the clinical outcome of this mixed tumor follows that of the more aggressive cell type [36]. Following WHO recommendations, we treated our patients as if they were affected by adenocarcinoma because it represented the most aggressive histologic component.

\section{Statement of Ethics}

The description of cases is retrospective, and the people involved maintained completely anonymous. The patients included in this case report had provided written informed consent to publish the images, and the authors have no ethical conflicts to disclose.

\section{Disclosure Statement}

The authors have no conflicts of interest to declare.

\section{References}

1 Kitajima T, Kaida S, Lee S, Haruta S, Shinohara H, Ueno M, et al. Mixed adeno(neuro)endocrine carcinoma arising from the ectopic gastric mucosa of the upper thoracic esophagus [PMID: 24139488 DOI: 10.1186/1477-7819-11-218]. World J Surg Oncol. 2013 Sep;11(1):218.

2 Harada K, Sato Y, Ikeda H, Maylee H, Igarashi S, Okamura A, et al. Clinicopathologic study of mixed adenoneuroendocrine carcinomas of hepatobiliary organs. Virchows Arch. 2012 Mar;460(3):281-9.

3 Gurzu S, Kadar Z, Bara T, Bara T Jr, Tamasi A, Azamfirei L, et al. Mixed adenoneuroendocrine carcinoma of gastrointestinal tract: report of two cases. World J Gastroenterol. 2015 Jan;21(4):1329-33.

4 Liu XJ, Feng JS, Xiang WY, Kong B, Wang LM, Zeng JC, et al. Clinicopathological features of an ascending colon mixed adenoneuroendocrine carcinoma with clinical serosal invasion. Int J Clin Exp Pathol. 2014 Aug;7(9):6395-8.

5 Acosta AM, Hamedani FS, Kajdacsy-Balla A, Wiley EL. Primary Mixed Adenoneuroendocrine Carcinoma of the Gallbladder in a 55-Year-Old Female Patient: A Case Report and Review of the Literature. Int J Surg Pathol. 2015 Aug;23(5):414-8.

6 Solcia E, Klöppel G, Sobin LH. Histopathological Typing of Endocrine Tumours. 2nd ed. Berlin: Springer; 2000.

7 Watanabe J, Suwa Y, Ota M, Ishibe A, Masui H, Nagahori K, et al. Clinicopathological and Prognostic Evaluations of Mixed Adenoneuroendocrine Carcinoma of the Colon and Rectum: A Case-Matched Study. Dis Colon Rectum. 2016 Dec;59(12):1160-7.

8 La Rosa S, Marando A, Sessa F, Capella C. Mixed adenoneuroendocrine carcinomas (MANECs) of the gastrointestinal tract: an update. Cancers (Basel). 2012 Jan;4(1):11-30.

9 Acosta AM, Wiley EL. Primary biliary mixed adenoneuroendocrine carcinoma (MANEC). A short review. Arch Pathol Lab Med. 2016 Oct;140(10):1157-62.

10 Düzköylü Y, Aras O, Bostancı EB, Keklik Temuçin T, Ulaş M. Mixed Adeno-Neuroendocrine Carcinoma; Case Series of Ten Patients with Review of the Literature. Balkan Med J. 2018 May;35(3):263-7.

11 Marusyk A, Polyak K. Tumor heterogeneity: causes and consequences. Biochim Biophys Acta. 2010 Jan;1805(1):105-17. 
12 Shia J, Tickoo SK, Guillem JG, Qin J, Nissan A, Hoos A, et al. Increased endocrine cells in treated rectal adenocarcinomas: a possible reflection of endocrine differentiation in tumor cells induced by chemotherapy and radiotherapy. Am J Surg Pathol. 2002 Jul;26(7):863-72.

13 Ahlgren G, Pedersen K, Lundberg S, Aus G, Hugosson J, Abrahamsson PA. Regressive changes and neuroendocrine differentiation in prostate cancer after neoadjuvant hormonal treatment. Prostate. 2000 Mar;42(4):274-9.

14 Bonkhoff H. Neuroendocrine cells in benign and malignant prostate tissue: morphogenesis, proliferation, and androgen receptor status. Prostate Suppl. 1998;8(S8 Suppl):18-22.

15 Shia J, Tickoo SK, Guillem JG, Qin J, Nissan A, Hoos A, et al. Increased endocrine cells in treated rectal adenocarcinomas: a possible reflection of endocrine differentiation in tumor cells induced by chemotherapy and radiotherapy. Am J Surg Pathol. 2002 Jul;26(7):863-72.

16 Adlakha H, Bostwick DG. Paneth cell-like change in prostatic adenocarcinoma represents neuroendocrine differentiation: report of 30 cases. Hum Pathol. 1994 Feb;25(2):135-9.

17 Wang KL, Yang Q, Cleary KR, Swisher SG, Correa AM, Komaki R, et al. The significance of neuroendocrine differentiation in adenocarcinoma of the esophagus and esophagogastric junction after preoperative chemoradiation. Cancer. 2006 0ct;107(7):1467-74.

18 Spiotto MT, Chung TD. STAT3 mediates IL-6-induced neuroendocrine differentiation in prostate cancer cells Prostate. 2000 Feb;42(3):186-95.

19 Abrahamsson PA. Neuroendocrine differentiation in prostatic carcinoma. Prostate. 1999 May;39(2):135-48.

20 Seretis E, Gavrill A, Agnantis N, Golematis V, Voloudakis-Baltatzis IE. Comparative study of serotonin and bombesin in adenocarcinomas and neuroendocrine tumors of the colon. Ultrastruct Pathol. 2001 NovDec;25(6):445-54.

21 Cox ME, Deeble PD, Lakhani S, Parsons SJ. Acquisition of neuroendocrine characteristics by prostate tumor cells is reversible: implications for prostate cancer progression. Cancer Res. 1999 Aug;59(15):3821-30.

22 Chen WY, Zeng T, Wen YC, Yeh HL, Jiang KC, Chen WH, et al. Androgen deprivation-induced ZBTB46-PTGS1 signaling promotes neuroendocrine differentiation of prostate cancer. Cancer Lett. 2019 Jan;440-441:35-46.

23 Ferrer L, Giaj Levra M, Brevet M, Antoine M, Mazieres J, Rossi G, et al. A Brief Report of Transformation From NSCLC to SCLC: Molecular and Therapeutic Characteristics. J Thorac Oncol. 2019 Jan;14(1):130-4.

24 Sequist LV, Waltman BA, Dias-Santagata D, Digumarthy S, Turke AB, Fidias P, et al. Genotypic and histological evolution of lung cancers acquiring resistance to EGFR inhibitors. Sci Transl Med. 2011 Mar;3(75):75ra26.

25 van Hagen P, Hulshof MC, van Lanschot JJ, Steyerberg EW, van Berge Henegouwen MI, Wijnhoven BP, et al.; CROSS Group. Preoperative chemoradiotherapy for esophageal or junctional cancer. N Engl J Med. 2012 May;366(22):2074-84.

26 Cunningham D, Allum WH, Stenning SP, Thompson JN, Van de Velde CJ, Nicolson M, et al.; MAGIC Trial Participants. Perioperative chemotherapy versus surgery alone for resectable gastroesophageal cancer. $\mathrm{N}$ Engl J Med. 2006 Jul;355(1):11-20.

27 La Rosa S, Marando A, Furlan D, Sahnane N, Capella C. Colorectal poorly differentiated neuroendocrine carcinomas and mixed adenoneuroendocrine carcinomas: insights into the diagnostic immunophenotype, assessment of methylation profile, and search for prognostic markers. Am J Surg Pathol. 2012 Apr;36(4):601-11.

28 Kim BS, Park YS, Yook JH, Kim BS. Comparison of relapse-free survival in gastric neuroendocrine carcinoma (WHO grade 3) and gastric carcinoma. Therap Adv Gastroenterol. 2017 May;10(5):407-15.

29 Ishida M, Sekine S, Fukagawa T, Ohashi M, Morita S, Taniguchi H, et al. Neuroendocrine carcinoma of the stomach: morphologic and immunohistochemical characteristics and prognosis. Am J Surg Pathol. 2013 Jul;37(7):949-59.

30 Zhang P, Wang W, Lu M, Zeng C, Chen J, Li E, et al. Clinicopathological features and outcome for neuroendocrine neoplasms of gastroesophageal junction: A population-based study. Cancer Med. 2018 Sep;7(9):4361-70.

31 Scardoni M, Vittoria E, Volante M, Rusev B, Bersani S, Mafficini A, et al. Mixed adenoneuroendocrine carcinomas of the gastrointestinal tract: targeted next-generation sequencing suggests a monoclonal origin of the two components. Neuroendocrinology. 2014;100(4):310-6.

32 Shia J, Tang LH, Weiser MR, Brenner B, Adsay NV, Stelow EB, et al. Is nonsmall cell type high-grade neuroendocrine carcinoma of the tubular gastrointestinal tract a distinct disease entity? Am J Surg Pathol. 2008 May;32(5):719-31.

33 Ishida M, Sekine S, Fukagawa T, Ohashi M, Morita S, Taniguchi H, et al. Neuroendocrine carcinoma of the stomach: morphologic and immunohistochemical characteristics and prognosis. Am J Surg Pathol. 2013 Jul;37(7):949-59.

34 Jesinghaus M, Konukiewitz B, Keller G, Kloor M, Steiger K, Reiche M, et al. Colorectal mixed adenoneuroendocrine carcinomas and neuroendocrine carcinomas are genetically closely related to colorectal adenocarcinomas. Mod Pathol. 2017 Apr;30(4):610-9.

35 La Rosa S, Inzani F, Vanoli A, Klersy C, Dainese L, Rindi G, et al. Histologic characterization and improved prognostic evaluation of 209 gastric neuroendocrine neoplasms. Hum Pathol. 2011 Oct;42(10):1373-84. 


\section{Case Reports in Oncology}

\begin{tabular}{l|l}
\hline Case Rep Oncol 2019;12:434-442 \\
\hline DOI: 10.1159/000501200 & $\begin{array}{l}\text { ○ 2019 The Author(s). Published by S. Karger AG, Basel } \\
\text { www.karger.com/cro }\end{array}$ \\
\hline
\end{tabular}

Oneda et al.: Diagnosis of Mixed Adenoneuroendocrine Carcinoma (MANEC) after Neoadjuvant Chemotherapy

36 Lee HH, Jung CK, Jung ES, Song KY, Jeon HM, Park CH. Mixed exocrine and endocrine carcinoma in the stomach: a case report. J Gastric Cancer. 2011 Jun;11(2):122-5.

37 Hamada Y, Oishi A, Shoji T, Takada H, Yamamura M, Hioki K, et al. Endocrine cells and prognosis in patients with colorectal carcinoma. Cancer. 1992 Jun;69(11):2641-6.

38 Syversen U, Halvorsen T, Mårvik R, Waldum HL. Neuroendocrine differentiation in colorectal carcinomas. Eur J Gastroenterol Hepatol. 1995 Jul;7(7):667-74.

39 Yin J, Liang Y, Wang H. [Significance of endocrine cells and their hormones in colorectal cancer]. Zhonghua Zhong Liu Za Zhi. 1997 May;19(3):192-5

40 Ferrero S, Buffa R, Pruneri G, Siccardi AG, Pelagi M, Lee AK, et al. The prevalence and clinical significance of chromogranin A and secretogranin II immunoreactivity in colorectal adenocarcinomas. Virchows Arch. 1995;426(6):587-92.

41 Lapertosa G, Baracchini P, Delucchi F. Prevalence and prognostic significance of endocrine cells in colorectal adenocarcinomas. Pathologica. 1994 Apr;86(2):170-3.

42 Mori M, Mimori K, Kamakura T, Adachi Y, Ikeda Y, Sugimachi K. Chromogranin positive cells in colorectal carcinoma and transitional mucosa. J Clin Pathol. 1995 Aug;48(8):754-8.

43 Smith DM Jr, Haggitt RC. The prevalence and prognostic significance of argyrophil cells in colorecta carcinomas. Am J Surg Pathol. 1984 Feb;8(2):123-8.

44 Paspala A, Machairas N, Prodromidou A, Spartalis E, Ioannidis A, Kostakis ID, et al. Management of MANEC of the colon and rectum: A comprehensive review of the literature. Mol Clin Oncol. 2018 Aug;9(2):219-22.
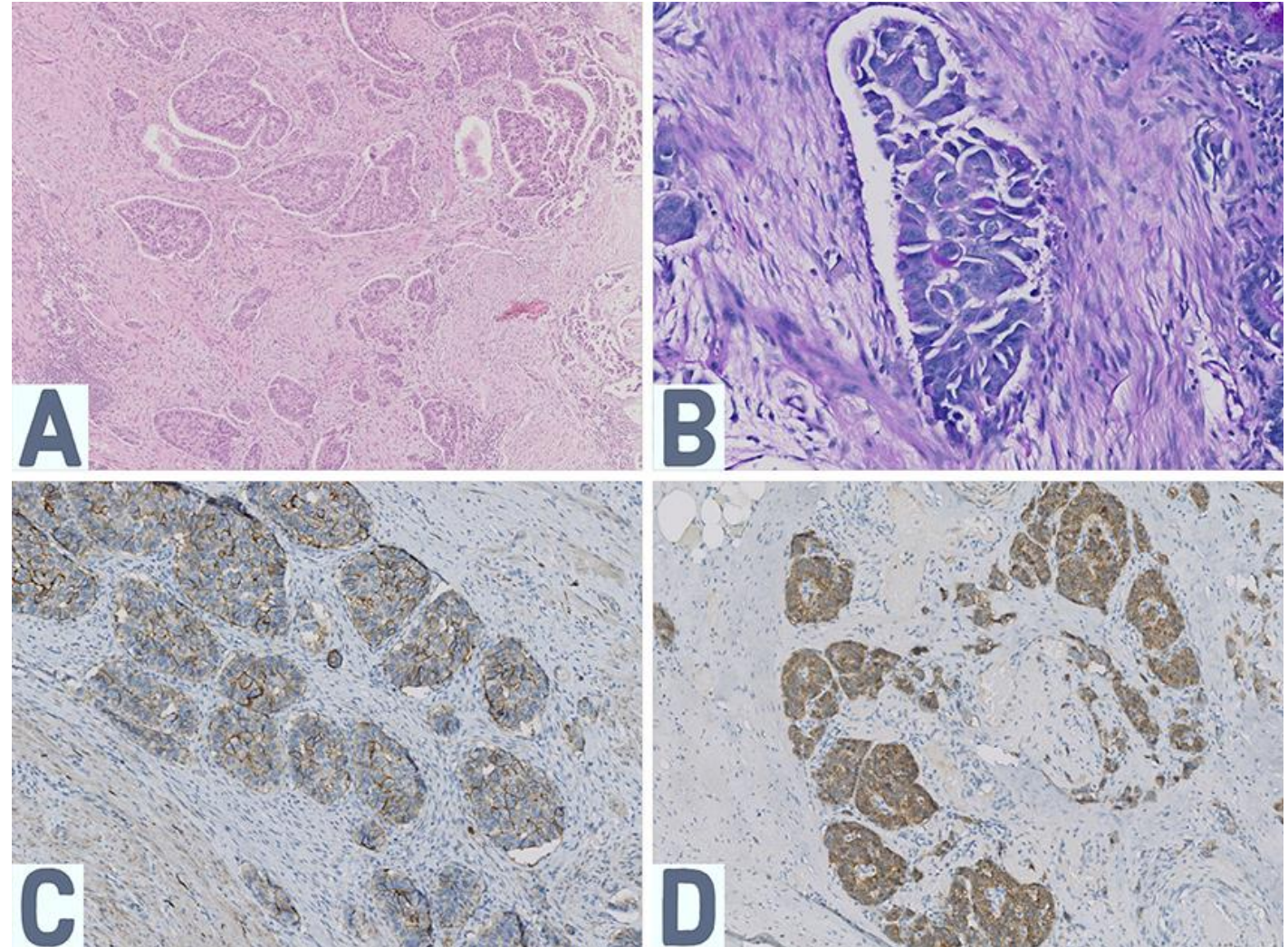

Fig. 1. A. The tumor consists of clusters of glandular structures (H\&E stain, $40 \times$ magnification). B. Drop of mucus in violet near nuclei (PAS-D +). C. Cells marked by the neuroendocrine marker CD56 (10× magnification). D. Neoplastic cells marked by neuroendocrine marker synaptophysin. 


\section{Case Reports in Oncology}

\begin{tabular}{l|l}
\hline Case Rep Oncol 2019;12:434-442 \\
\hline DOI: 10.1159/000501200 & $\begin{array}{l}\text { c 2019 The Author(s). Published by S. Karger AG, Basel } \\
\text { www.karger.com/cro }\end{array}$ \\
\hline
\end{tabular}

Oneda et al.: Diagnosis of Mixed Adenoneuroendocrine Carcinoma (MANEC) after Neoadjuvant Chemotherapy
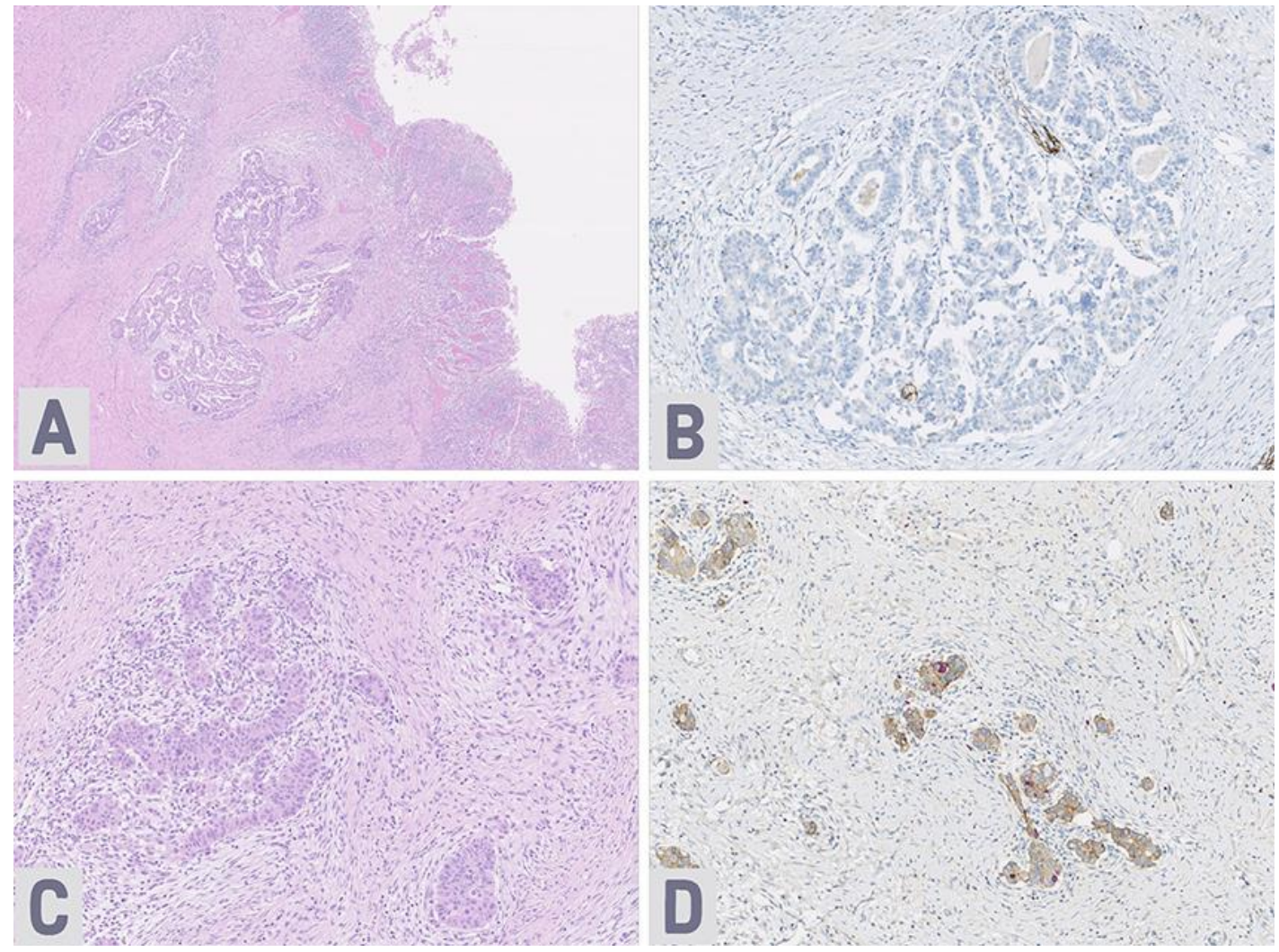

Fig. 2. A. Morphology of the tumor in the neuroendocrine component (H\&E stain, $2.5 \times$ magnification). B. Epithelial-glandular part of the tumor, CD56 negative. C. Details of the epithelial component (H\&E stain, $10 \times$ magnification) D. Neoplastic cells marked by neuroendocrine marker synaptophysin in a double stain with ki67 for the neuroendocrine component. 